\title{
Spatial regulation of engrailed expression in the Drosophila embryo
}

\author{
Michael P. Weir, ${ }^{1}$ Bruce A. Edgar, ${ }^{1,2}$ Thomas Kornberg, $^{1}$ and Gerold Schubiger ${ }^{3}$ \\ ${ }^{1}$ Department of Biochemistry and Biophysics, University of California, San Francisco, California 94143 ; ${ }^{2}$ Department of \\ Genetics and ${ }^{3}$ Department of Zoology, University of Washington, Seattle, Washington 98195 USA
}

\begin{abstract}
Novel patterns of engrailed RNA were observed in early Drosophila embryos injected with cycloheximide, an inhibitor of protein synthesis. From these patterns, we infer that there are several superimposed systems of spatial regulation which in combination localize engrailed expression in the embryo. Activation of engrailed transcription progresses with an anterior-to-posterior polarity. Superimposed are systems of negative regulation that repress expression in the anterior $30 \%$ of the embryo and in the interbands between stripes. We suggest that products of known segmentation genes are the repressors that suppress engrailed expression in interbands.
\end{abstract}

[Key Words: Segmentation; RNA localization; Drosophila embryogenesis; cycloheximide]

Received April 8, 1988; revised version accepted July 18, 1988.

The subdivision of the Drosophila embryo into a linear series of segments depends upon several classes of genes. The combined activities of the coordinate, gap, pair-rule, segment-polarity, and homeotic genes together specify the location, size, and identity of the individual metameres. Without the function of these segmentation and homeotic genes, segments do not form properly, are of abnormal size, or do not follow the developmental pathway characteristic of their location (reviewed by Akam 1987).

The genes that generate the segmental pattern are expressed in regions which correspond to their respective domains of function. Thus, for example, the engrailed gene, which is required for the development of the posterior compartments of segments, is expressed in all posterior compartment cells. In embryos at the cellular blastoderm stage, in which the posterior compartment primordia are arranged as a single-cell-wide band in each segment, the engrailed gene is expressed in a reiterated series of single-cell-wide stripes, one stripe per metamere (DiNardo et al. 1985; Fjose et al. 1985; Kornberg et al. 1985).

Because they are expressed in segmental intervals, products of the engrailed and other segmentation genes may be considered as molecular markers of segments. Probing how these genes are spatially regulated therefore offers an experimental approach to understanding the mechanisms involved in segmentation. To date, such studies have included several strategies. (1) Genetic studies have indicated that mutations in segmentation genes disrupt the expression patterns of other segmentation genes, suggesting that a hierarchical network of gene-gene interactions plays a role in their patterning (Carroll and Scott 1986; Harding et al. 1986; Howard and
Ingham 1986; Jackle et al. 1986; Macdonald et al. 1986; DiNardo and O'Farrell 1987; Perrimon and Mahowald 1987). (2) Transformation studies using portions of the fushi tarazu (ftz) gene promoter have identified DNA sequences required for spatially regulated expression (Hiromi et al. 1985; Hiromi and Gehring 1987). (3) Descriptions of the expression patterns of genes such as $f t z$, paired (prd), engrailed, and gooseberry have indicated that segmentation evolves through a series of stages which progressively define smaller intervals, the segment interval being the mature one (Weir and Kornberg 1985; Kilchherr et al. 1986; Baumgartner et al. 1987). (4) Complementing these studies, we have described another approach that uses inhibitors of RNA ( $\alpha$-amanitin) and protein (cycloheximide) synthesis to block metabolic functions involved in the pattern formation process.

We first examined the effects of inhibitors on the expression of the pair-rule gene, fushi tarazu. We found that ftz RNA has a short half-life, an observation that is consistent with the rapid evolution of $f t z$ expression patterns. The processes that pattern $f t z$ RNA are sensitive to inhibition of protein synthesis, and the different responses that were observed in different parts of the embryo suggested the involvement of at least two separate and identifiable systems of regulation. One system inhibits expression of $\mathrm{ftz}$ in the polar regions of the embryo, and a second inhibits ftz expression in the regions between its seven stripes (Edgar et al. 1986b).

To test whether similar mechanisms regulate the expression of other segmentation genes, we have extended this analysis to the engrailed gene. Novel patterns of engrailed transcription observed in the presence of cycloheximide indicate the existence of several superimposed 
systems of spatial regulation. Furthermore, they suggest how the combined functions of known segmentation genes generate the patterns of engrailed expression.

\section{Results}

\section{Normal engrailed expression patterns}

Drosophila embryogenesis begins with a series of 13 rapid and nearly synchronous nuclear divisions. During the 9th nuclear cycle, the nuclei migrate to the periphery of the embryo, and in the 14 th cycle, the rapid divisions pause for 60-90 $\mathrm{min}$, the nuclei elongate, and cell membranes separate the nuclei into individual cells (Rabinowitz 1941; Foe and Alberts 1983).

Transcripts from the engrailed gene have been detected by in situ hybridization in embryos about 20-30

Table 1. Frequencies of engrailed RNA patterns in cycloheximide-treated and control embryos

\begin{tabular}{|c|c|c|c|c|c|}
\hline \multirow[b]{2}{*}{ Type } & \multirow[b]{2}{*}{$\begin{array}{l}\text { en } \\
\text { pattern }\end{array}$} & \multicolumn{4}{|c|}{ Minutes AED, $22^{\circ} \mathrm{C}$} \\
\hline & & $\begin{array}{c}180 \min \\
|\%|\end{array}$ & $\begin{array}{c}190 \min \\
(\%)\end{array}$ & $\begin{array}{c}210 \mathrm{~min} \\
|\%|\end{array}$ & $\begin{array}{c}235 \min \\
(\%)\end{array}$ \\
\hline Control & $\begin{array}{c}\mathrm{A} \\
\mathrm{B} \\
\mathrm{C} \\
\mathrm{D} \\
|n|\end{array}$ & $\begin{array}{r}100 \\
0 \\
0 \\
0 \\
(23)\end{array}$ & & $\begin{array}{c}40 \\
12 \\
16 \\
32 \\
(25)\end{array}$ & $\begin{array}{c}0 \\
24 \\
29 \\
46 \\
(41)\end{array}$ \\
\hline Cyh (60 min) & $\begin{array}{c}\mathrm{A} \\
\mathrm{E} \\
\mathrm{F} \\
\mathrm{G} \\
|n|\end{array}$ & $\begin{array}{r}6 \\
83 \\
11 \\
0 \\
(18)\end{array}$ & $\begin{array}{r}5 \\
48 \\
43 \\
5 \\
(21)\end{array}$ & $\begin{array}{c}3 \\
21 \\
55 \\
21 \\
(33)\end{array}$ & $\begin{array}{c}0 \\
0 \\
9 \\
91 \\
(56)\end{array}$ \\
\hline Cyh $(90 \mathrm{~min})$ & $\begin{array}{c}\mathrm{A} \\
\mathrm{H} \\
\mathrm{I} \\
\mathrm{J} \\
(n)\end{array}$ & & $\begin{array}{c}7 \\
41 \\
33 \\
19 \\
(27)\end{array}$ & & \\
\hline
\end{tabular}

Control embryos were fixed at the times indicated; experimental embryos (Cyh, 60 or $90 \mathrm{~min}$ ) were injected at the times indicated and fixed either 60 or 90 min later. The continuous ranges of the control and experimental RNA patterns were classified into 10 discrete groups (Fig. 6A-J) as follows. (A) No signal; (B) one-stripe, pronounced expression in stripe 2 (Fig. la); (C) intermediate pattern, pronounced expression in two or more of stripes $1-8$ and 12 (Fig. 1b); (D) complete or nearly complete pattern, pronounced expression in additional stripes besides stripes $1-8$ and 12 (Fig. lC); (E) anterior-dorsal expression alone (Fig. $3 \mathrm{a}) ;\langle\mathbf{F})$ intermediate pattern, pronounced expression in stripe fusions $0+1$ and $2+3$, and expression in anterior-dorsal and/or more posterior locations (Fig. 3b,c); (G) complete or nearly complete pattern, pronounced expression in seven stripe fusions (Fig. 3d,e and 4a); H, I, and J are equivalent to $D, E$, and F, respectively, except for the presence of considerably more interband expression (Fig. $5 a-c$, respectively). Frequencies of these patterns are presented in Table 1 as percentages of the total number of scored embryos (parentheses). Each embryo for the 180-, 210-, and 235-min timepoints was scored after reconstruction of 3-10 randomly chosen sections; for the 190-min time point, which was a separate experiment, 1-2 sections were scored for each embryo.
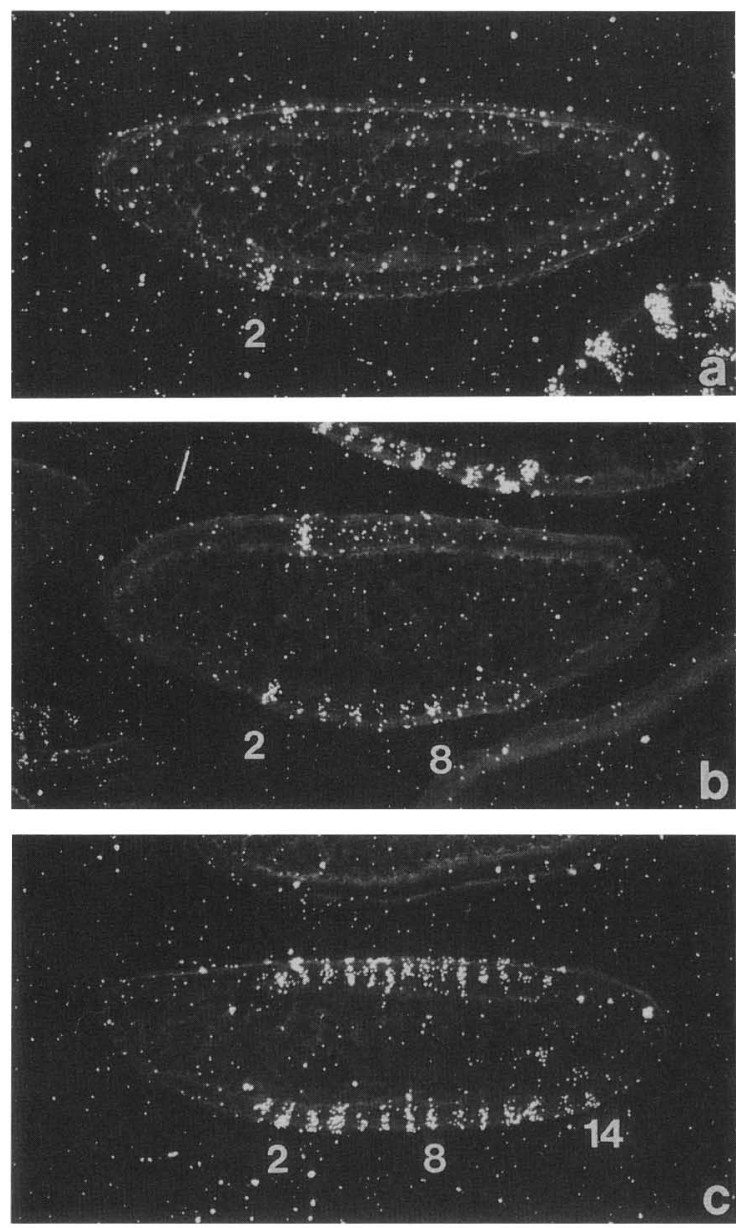

Figure 1. engrailed transcripts in uninjected embryos. Frozen sections of cycle 14 embryos were hybridized with an engrailed cDNA probe. $\left(\left[{ }^{3} \mathrm{H}\right]\right.$ RNA probe). Embryos are oriented anterior left, dorsal up. $(\mathrm{a}-\mathrm{c})$ Intermediate patterns in the development of the 14-stripe array.

min after the beginning of nuclear cycle 14 /Weir and Kornberg 1985; Table 1; Fig. 1). They are initially concentrated in a single stripe $1-2$ cells wide (stripe 2 in parasegment 2; Martinez-Arias and Lawrence 1985), approximately $60 \%$ from the posterior pole. For the subsequent 40-50 min, engrailed expression increases quantitatively and changes in pattern. Additional stripes of engrailed RNA appear with an overall anterior-to-posterior and ventral-to-dorsal order. Violating this general order of appearance, some of the stripes in the more posterior even-numbered parasegments form before those in more anterior odd-numbered ones (Fig. 1; Weir and Kornberg 1985). By the commencement of gastrulation, an array of 14 stripes has evolved.

During this developmental period of rapid changes in the pattern of engrailed expression, engrailed transcripts turn over rapidly. Northern analysis of RNA isolated from embryos that had been injected with $\alpha$-amanitin, an inhibitor of transcription initiation, indicated a halflife of 6-9 min for engrailed mRNA (Fig. 2A). This unusually small value is similar to those of fushi tarazu (ftz) (Edgar et al. 1986b), even-skipped, hairy, runt, 

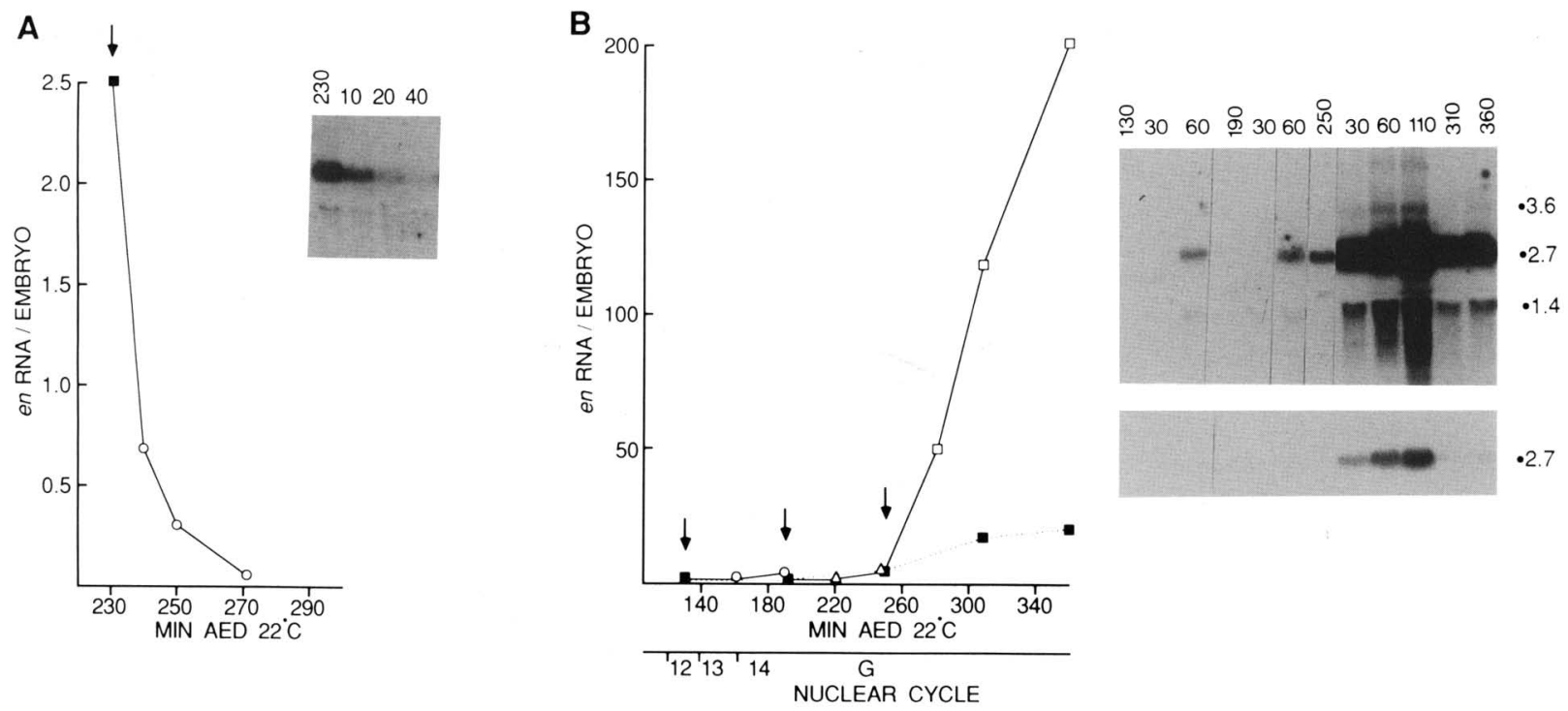

Figure 2. (A) Turnover of engrailed RNA in the embryo measured by $\alpha$-amanitin injection. The rate of turnover of engrailed RNA was determined as described previously (Edgar et al. 1986b) by blocking transcription with $\alpha$-amanitin and measuring by Northern analysis the amount of engrailed RNA that remained at increasing time intervals after injection. Embryos were injected at 230 min after egg deposition (AED; mid cycle 14) (arrow). The vertical number on the gel indicates min AED for uninjected embryos. The horizontal numbers immediately following indicate the times of incubation after injection at this time. Densitometry of the gel was used for the graph which indicates that the $2.7-\mathrm{kb}$ engrailed RNA is short-lived with a half-life of $6-9$ min. The same blot was hybridized with a probe for ribosomal protein 49 mRNA (rp49). Unlike the engrailed transcripts, rp 49 mRNA was stable after injection of $\alpha$-amanitin (not shown). (B) Accumulation of engrailed RNA after injection of cycloheximide. Cycloheximide was injected at cycles 12 (130 min AED), early 14 (190 min AED), and late 14 (250 min AED) (arrows). RNA was measured by Northern analysis at 30, 60 , and $110 \mathrm{~min}$ postinjection. (Upper gel) $12-\mathrm{hr}$ and (lower gel) $2-\mathrm{hr}$ exposures of the Northern blot are illustrated with lanes marked as in A. engrailed RNA (2.7 kb) accumulated in uninjected control embryos (dotted line) and after injection of cycloheximide at the different times (solid lines). The lower horizontal axis indicates nuclear cycles (with slashes at the midpoints of mitosis). G indicates the onset of gastrulation.

Krüppel, and hunchback (B.A. Edgar and G. Schubiger, unpubl.), genes whose patterns of expression also change rapidly during pre-gastrula development.

\section{Effects of cycloheximide}

Injection of cycloheximide into precellular Drosophila embryos arrests protein synthesis rapidly and blocks nuclear cycling in the subsequent $\mathrm{G}_{2}$ phase (Zalokar and Erk 1976; Edgar and Schubiger 1986). As with other cell types, the presence of cycloheximide also stabilizes mRNAs (Lindquist et al. 1982). Quantities of engrailed RNA increased significantly in the presence of cycloheximide (Fig. 2B). Accumulation of engrailed RNA was most pronounced when cycloheximide was administered late in cycle 14.

To determine whether the spatial pattern of engrailed transcripts was altered in the presence of cycloheximide, injected embryos were subjected to in situ hybridization. Embryos in nuclear cycles 8, 10,12,13, and three stages within cycle 14, were injected with the drug. After 60 or $90 \mathrm{~min}$ of incubation, embryos were fixed, sectioned, and hybridized with an engrailed cDNA probe. Uninjected control embryos were processed in parallel and were fixed as the experimental embryos were injected.

Embryos injected during cycles 8, 10,12, and 13 and incubated for $60 \mathrm{~min}$ did not have detectable engrailed transcripts. Injection during cycle 14 resulted in an array of patterns of engrailed expression not characteristic of normal embryos (Figs. 3-5). engrailed RNA was observed in regions where it is not normally detected-between stripes, and in the anterior third of the embryo 170-100\% egg length, EL, measured from the posterior end). In addition, appearance of the more posterior stripes (which characterize the maturation of normal engrailed expression/ was blocked. The type of novel pattern was a function of both the time of injection, and the time of incubation after injection.

The patterns of engrailed expression in embryos incubated for 60 or $90 \mathrm{~min}$ after cycloheximide injection were similar. However, with $60 \mathrm{~min}$ of incubation, high levels of extra engrailed expression were observed only in every other interband, whereas with $90 \mathrm{~min}$ of incubation, high levels were observed in all the interbands (see below). We describe first the 60-min patterns.

\section{Cycloheximide-induced patterns after $60 \mathrm{~min}$ of incubation}

Embryos injected early in cycle 14 (approximately 180 min after egg deposition, AED) and incubated for $60 \mathrm{~min}$ expressed the engrailed gene in a broad anterior-dorsal patch between approximately $75 \%$ and $95 \%$ EL (Fig. 3a). Control embryos $180 \mathrm{~min}$ AED had no detectable en- 
Figure 3. engrailed transcripts in cycloheximide-injected embryos incubated for $60 \mathrm{~min}$. (a-e) are examples from the range of novel patterns of engrailed expression after injection of cycloheximide during cycle 14 , and incubation for $60 \mathrm{~min}$. We infer from Table 1 that $a-e$ were injected at progressively later times. Sections are oriented anterior left, dorsal up $/ c$ is a grazing section). Compared to uninjected control embryos (Fig. 1), extra engrailed expression was observed in the anteriordorsal region (arrows: a,b), stripe 0 (arrowheads: $c-e$ ), and in the interbands between stripes $0+1,2+3$ etc. (brackets: e) (see Fig. 4).

grailed RNA; control embryos 60 min older had an array of 14 reiterated stripes from $10 \%$ to $70 \%$ EL (Figs. la-c and 6 ; Table 1).

Injections later in cycle 14 resulted in a range of striped engrailed patterns with progressively more expression in the posterior portions of the embryo (Figs. $3 \mathrm{~b}-\mathrm{e}$ and 6; Table 1). Patterns observed after injection during mid cycle 14 (210 min AED) had two prominent bands of expression centered at $70 \%$ and $60 \%$ EL. In addition, engrailed RNA was localized in these embryos in the anterior-dorsal region and/or weakly in more posterior stripes (Fig. $3 \mathrm{~b}, \mathrm{c}$ ). The extent of maturation of striped expression toward the posterior pole of the embryo was significantly less than in uninjected controls of the same age (60 min after the time of injection). Comparison with the expression in older embryos that had formed a cephalic furrow (see Fig. 4), indicates that in these younger cycloheximide-treated embryos, the second of the two prominent bands (at $60 \% \mathrm{EL}$ ) encompasses the sites of stripes 2 and 3 as well as the intervening regions. The prominent band that is more anterior (at $70 \% \mathrm{EL}$ ) corresponds to a portion of the embryo that encompasses stripe 1 , as well as adjacent regions that include what are here referred to as stripe 0 and the 0-1 interband. Although RNA localized in the anteriordorsal patch and stripe 0 has not been observed in normal embryos, expression of engrailed protein has been detected at these sites with the more sensitive assay made possible by antibodies directed against the engrailed protein. These sites stain very weakly in cycle 14 embryos (T. Karr, M. Weir, and T. Kornberg, unpubl.), and only become prominent during germ-band elongation (DiNardo et al. 1985). Comparison with fate maps of embryos suggests that the anterior-dorsal patch is in the presumptive clypeolabral region, and stripe 0 is in the antennal region (Campos-Ortega and Hartenstein 1985).

Embryos injected late in cycle 14 just before gastrulation (approximately $235 \mathrm{~min}$ AED) differed from those injected during mid cycle 14 (210 min AED) in that they lacked the anterior-dorsal patch of expression and had banded expression that extended further toward the posterior end (Fig. 3c-e). Stripes corresponding to stripe numbers $0+1$ and $2+3$ and their respective interbands were present, as were five additional paired stripes (corresponding to numbers $4+5,6+7, \ldots, 12+13$ ). A narrow stripe (corresponding to number 14) near the posterior pole was also prominent (Fig. 3e). Thus, the progressive anterior-posterior appearance of stripes of engrailed ex-
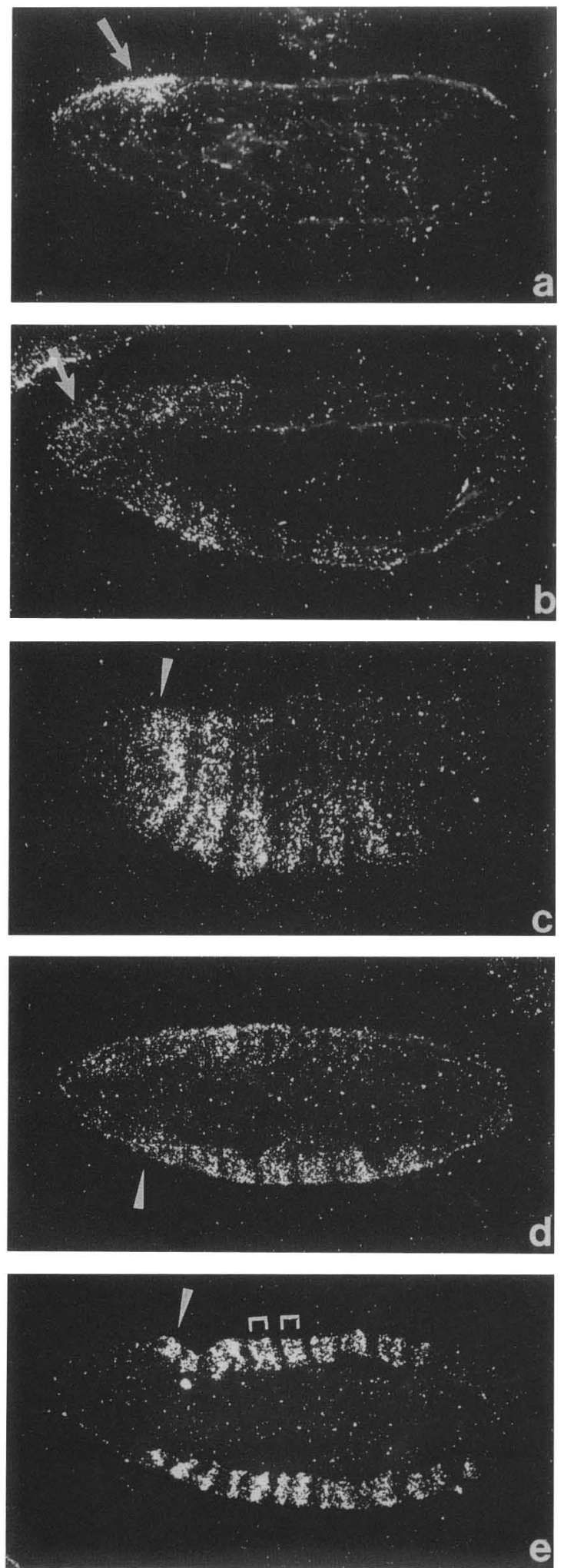

pression became increasingly less sensitive to the presence of cycloheximide as embryos matured (Fig. 6; Table 1).

The broad stripes in injected embryos can be described as the result of ectopic expression in the interband re- 
Figure 4. engrailed expression in gastrulated embryos. (a) engrailed RNA in a frozen section of a gastrulated embryo injected with cycloheximide and incubated for $60 \mathrm{~min}$. (b) An optical section of an uninjected gastrulated embryo stained with a monoclonal antibody against the engrailed protein. Arrows in a and b point to equivalent stripes in the posterior part of the cephalic furrow: The alternating pattern in $b$ implies that the identity of this stripe is stripe 2 (parasegment 2). Hence, the pairing of stripes in $(a)$ is $0+1,2+3$ etc. (brackets).
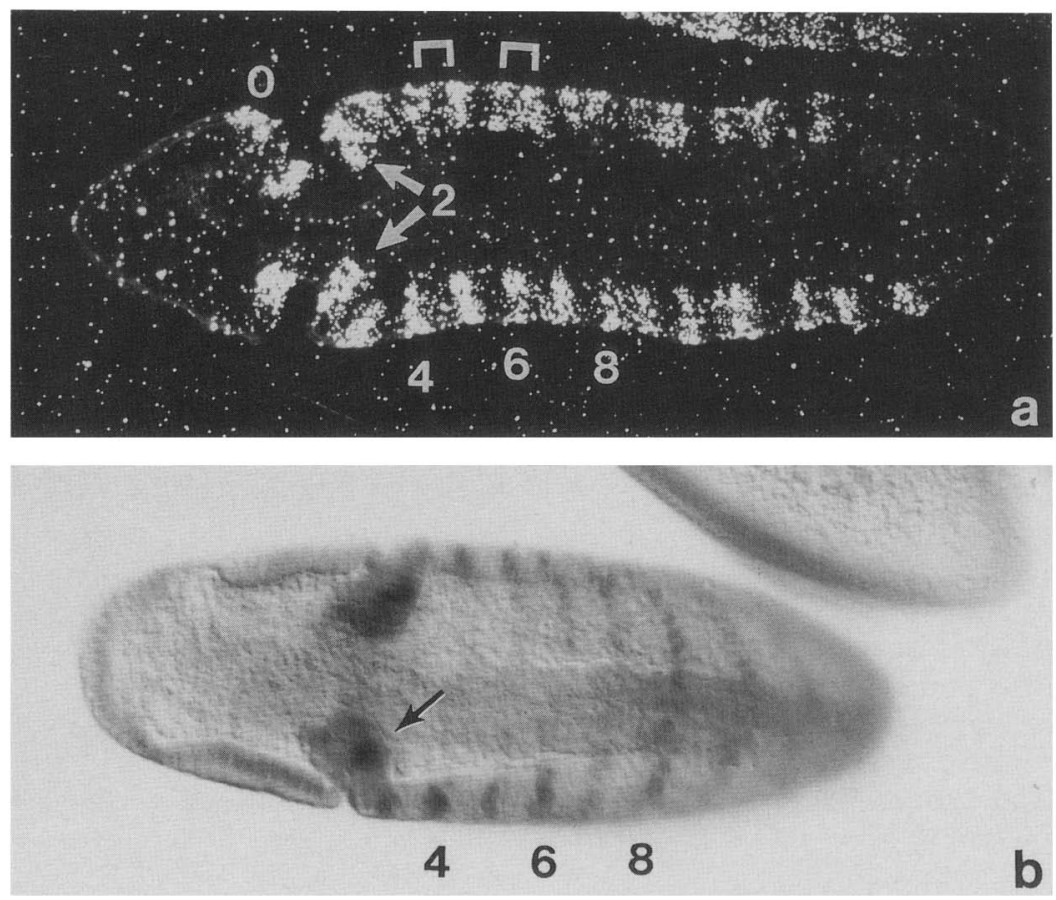
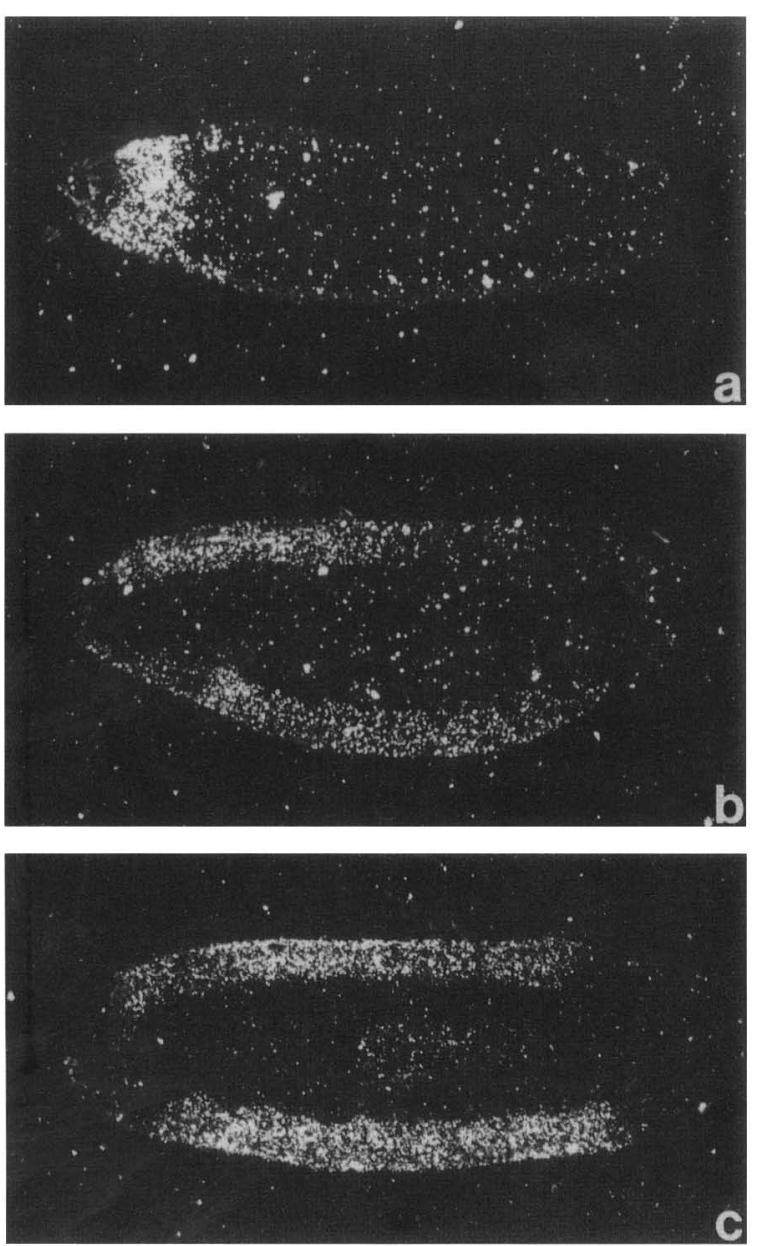

gions, between pairs of stripes. The level of expression in the interband regions was graded, with progressively higher levels in dorsal and posterior regions of the embryo. Interband expression was relatively lower in embryos injected during mid or late cycle 14, resulting in apparent splitting of the broad bands (Figs. $3 \mathrm{c}-\mathrm{e}$ and $4 \mathrm{a}$ ). Such splitting was often asymmetrical, with a broader region of expression in the posterior part of each fused stripe (Fig. 3c,d).

\section{Expression after 90 min of incubation with cycloheximide}

To evaluate whether the time of incubation post injection affected the observed patterns of engrailed expression, in a separate experiment, embryos injected at mid cycle 14 (approximately $190 \mathrm{~min}$ AED) were incubated for either 60 or $90 \mathrm{~min}$. The patterns observed after either $60 \mathrm{~min}$ or $90 \mathrm{~min}$ of incubation were similar (Table 1). Both the progression of expression from the anterior to the posterior portions of the embryo and the quantity of engrailed RNA in the anterior portion of the embryo were dependent on the time of injection and were independent of the time of incubation (Fig. 6). Anteriordorsal expression was only observed after injection into early or mid cycle 14 embryos, but not in late cycle 14

Figure 5. engrailed expression $90 \mathrm{~min}$ after cycloheximide injection. $(\mathrm{a}-\mathrm{c})$ Examples of the patterns of engrailed expression after incubation with cycloheximide for $90 \mathrm{~min}$. We infer from the frequencies of these patterns (Table 1) that $a-c$ were injected at progressively later times (see Fig. 6). Note the almost uniform expression in all the interbands. (a) Grazing frontal section showing anterior dorsal expression. (b) Sagittal section with an intermediate pattern. (c) Approximately frontal; the anterior-most signal is in the region of stripe 0 . 


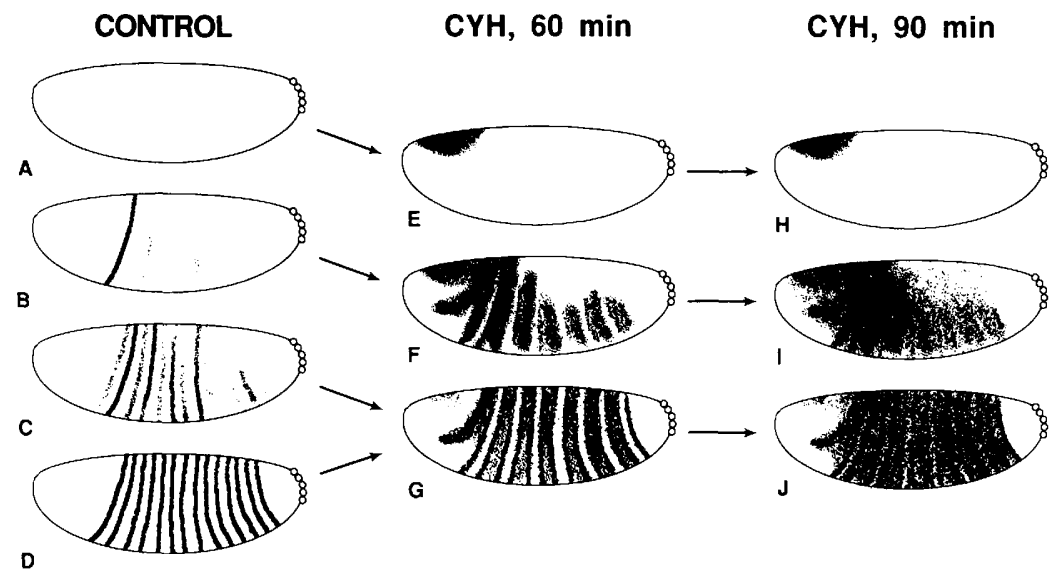

Figure 6. Schematic representation of normal and drug-induced engrailed RNA patterns. $(A-D)$ The normal progression in engrailed expression that occurs in cycle 14 (Weir and Kornberg 1985). (E-G) The range of engrailed patterns at $60 \mathrm{~min}$ after injection of cycloheximide; $(H-I)$ patterns after $90 \mathrm{~min}$. Arrows indicate the temporal relationship between these patterns (see Table 1). Patterns $E-J$ were derived from serial reconstruction of over 20 embryos. Approximately uniform expression is illustrated schematically in $/$; note that expression was often slightly reduced in narrow stripes one to two cells wide, spaced at two segment intervals.

embryos (Fig. 5a,b). Expression in the region of stripe 0 was pronounced with injections in mid and late cycle 14 , but was not observed in embryos injected early in cycle 14 (Fig. 5b,c).

The patterns of engrailed expression after $90 \mathrm{~min}$ of incubation differed from those after $60 \mathrm{~min}$ of incubation in one significant aspect: In addition to expression in the interbands posterior to the even-numbered stripes, high levels of expression were also observed in the interbands posterior to the odd-numbered stripes. Thus, $90 \mathrm{~min}$ after administration of cycloheximide, engrailed expression was virtually uniform in the mid portion of the embryo (Figs. 5 and 6).

\section{Discussion}

Injection of cycloheximide into precellular Drosophila embryos altered the expression of the engrailed gene in three fundamental ways: The anterior-to-posterior process of transcription activation was arrested, and transcription was activated abnormally in the anterior third of the embryo and in the interband regions. Since these three effects can be distinguished both by the regions affected, and by the developmental times during which they were elicited, we suggest that three separate systems of regulation are involved in generating the normal patterns of engrailed expression. The first system induces expression with a generally anterior-toposterior temporal sequence, the second suppresses expression anterior to the region of the future cephalic furrow, and the third suppresses expression in the interbands.

Some of these effects are similar to the responses to cycloheximide of the systems that regulate the $\mathrm{ftz}$ gene (Edgar et al. 1986b). The presence of cycloheximide alters patterns of transcription of the $f t z$ gene by permitting expression in the interband regions and by arresting the processes that normally limit expression to the middle portion of the embryo. Hence, the mechanisms that generate the striped $f t z$ and engrailed patterns are similar in that they both involve cycloheximide-sensitive suppression of gene activity in the interbands and polar regions of the embryo. The responses to cycloheximide differed, however, in that unlike $f t z$, the engrailed gene is activated in an anterior-to-posterior progression during cycle 14, and this activation also requires new protein synthesis. Indeed, Northern analysis of RNA isolated from embryos injected with cycloheximide revealed significant accumulation of engrailed RNA only during late cycle 14, whereas ftz RNA accumulates with earlier injections in cycles 12, and early 14 (cf., Fig. 2 with Fig. 1 in Edgar et al. 1986b).

Formally, the effects observed following administration of cycloheximide indicate a sensitivity to perturbing cellular metabolism, and correlating such effects with a requirement for specific regulatory proteins can only be hypothetical. However, given the many interactions that have been observed between the segmentation genes and the apparent cross-regulatory network that patterns their expression (reviewed in Akam 1987), we suggest here an interpretation of our results which assumes that the effects of cycloheximide on engrailed expression are primarily a consequence of inhibiting the synthesis of the protein products of other segmentation genes. This model accounts for the effects both of cycloheximide and of mutations in other segmentation genes on the regulation of engrailed expression.

Consider the differential regulation of engrailed expression during the formation of bands and interbands in a cycle 14 embryo. Since in the presence of cycloheximide additional expression was observed in the interband regions, we suggest that the drug inhibits the synthesis of repressors that normally function in these regions, and that the formation of engrailed stripes normally depends upon the negative regulation conferred by these repressors. In the presence of cycloheximide, the negative regulation is lost, presumably because the repressors are short-lived and, in the absence of protein synthesis, are no longer replenished.

This indication that engrailed is negatively regulated is in contrast to results of genetic studies which suggest that engrailed is under positive control by a number of pair-rule genes. Embryos mutant in $\mathrm{ftz}$ or odd-paired (opa) lack engrailed stripes in even-numbered parasegments; mutants in paired (prd) lack stripes in odd-numbered parasegments; even-skipped (eve) mutants lack both even and odd stripes, although only odd stripes are removed in weaker eve mutants (Harding et al. 1986; 
a

parasegments

Normal en stripes

Activity of:

repression 1

repression 2

b

Expression of hypothetical

negative regulators

Expression of positive regulators

R1:

R2

B :

A

B

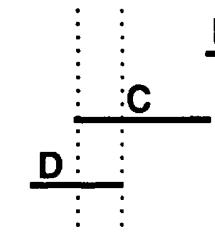

R1

R1: :

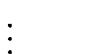

R2

R4
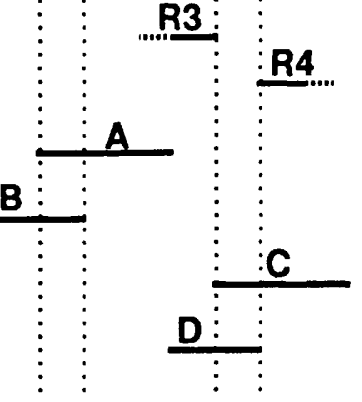

C

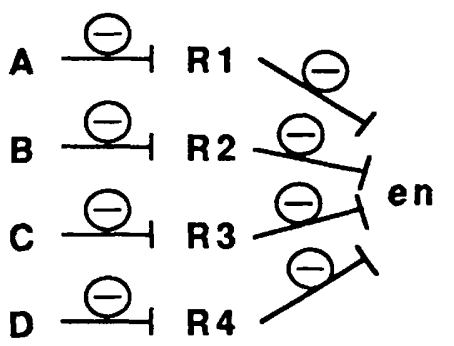

d

$$
\begin{aligned}
& \text { parasegments } \\
& \text { en expression } \\
& \text { repression } \\
& \text { inactive } \\
& \text { repression } \\
& \text { and repression } \\
& \text { inactive } \\
& \text { A or } B \\
& \text { inactive } \\
& C \text { or D } \\
& \text { inactive }
\end{aligned}
$$

en expression with:

repression 1

repression 1

and repression 2

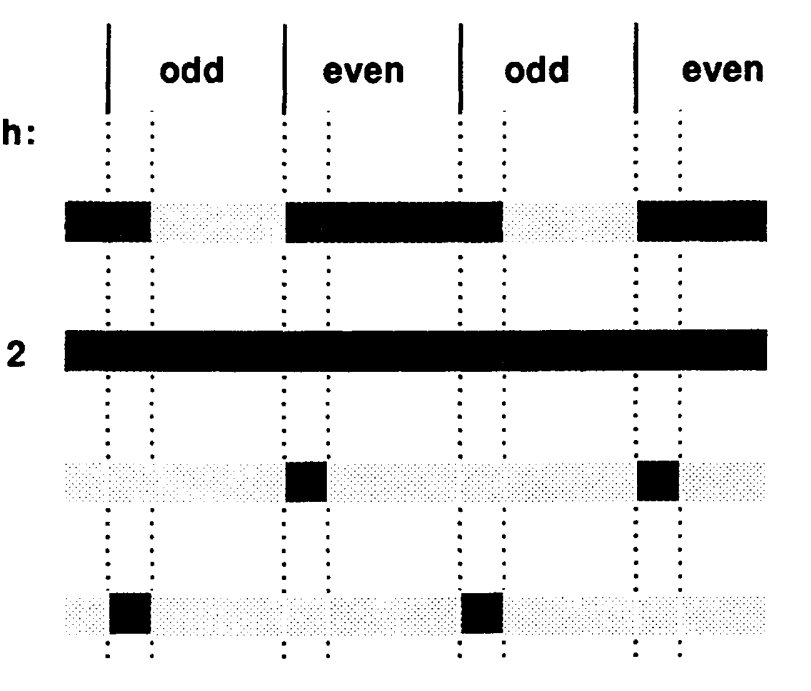

Experimental Conditions

cyh $60^{\circ}$

cyh $90^{\circ}$

eve ${ }^{-}$or pró

$\mathrm{ftz}^{-}$or

opa-

Figure 7. (See facing page for legend.) 
Howard and Ingham 1986; MacDonald et al. 1986; DiNardo and O'Farrell 1987; Ingham et al. 1988). These phenotypes have led to proposals that these pair-rule genes are positive regulators of engrailed, and in particular, that $f t z$ and opa are positive regulators in the even-numbered engrailed stripes, and prd and eve in the odd ones (Ingham et al. 1988). This idea is consistent with the known spatial expression of these genes (see Fig. $7 \mathrm{~b}$ ).

How can these indications of both positive and negative control of engrailed be reconciled? One possibility is that the formation of engrailed stripes requires positive regulation by pair-rule genes, whereas the maintenance of striped expression depends upon negative regulation in the engrailed interbands. An alternative possibility is that the formation of engrailed stripes is indeed controlled by repressors that act at interband locations, and that pair-rule genes confer positive regulation by inactivating these repressors at the sites where engrailed stripes ultimately form. This inactivation could for example operate by shutting down the synthesis (by transcriptional repression), or modifying the action (by antirepression) of the putative repressor proteins.

The known spatial expression of the positive regulators $f t z$ and $e v e$ suggests that they define the anterior borders of the engrailed stripes (Lawrence et al. 1987; see Fig. $7 \mathrm{~b}$ ). Similarly, although not yet directly tested, it is likely that prd and opa define the posterior borders of the engrailed stripes (Ingham et al. 1988). If the direct regulators of engrailed are in fact negative, then the same borders could be defined by repressors expressed on the opposite sides of each border. This idea is illustrated by the hypothetical repressors R1-R4 in Figure $7 \mathrm{~b}$. To account for the positive regulation of engrailed exerted by eve, prd, ftz, and opa (A-D, Fig. 7b), it is possible that they regulate engrailed indirectly by negatively regulating $\mathrm{R} 1-\mathrm{R} 4$, respectively (Fig. $7 \mathrm{c}$ ).

What might be the identities of these hypothetical repressors of engrailed? In principle, they could be the products of other pair-rule genes and hence have different identities in every other engrailed interband as illustrated in Figure $7 \mathrm{~b}$. Alternatively, they could be coded by segment-polarity genes and have the same identities in corresponding cell rows of each interband (e.g., R1 and R3 could be the same repressor). Loss-offunction mutants in the segmentation genes encoding repressors of engrailed would be expected to have extra expression of engrailed in parts of the interband. Thus far, this has been observed for example in mutants of the pair-rule gene, odd-skipped, and the segment-polarity gene, naked. Mutants of odd-skipped have extra expression of engrailed protein in the cell row immediately behind the even-numbered engrailed stripes (DiNardo and O'Farrell 1987). Mutants of naked have extra expression of engrailed RNA in the cell row immediately behind both the even- and odd-numbered engrailed stripes (Martinez-Arias et al. 1988), and we have confirmed that the expression of engrailed protein is also in broader stripes than normal (unpubl.). Hence, these two genes are candidates for negative regulators of engrailed.

A notable feature of the effects of cycloheximide on engrailed expression is the differential transcript accumulation in the interbands in the odd- and even-numbered parasegments. With incubation for $60 \mathrm{~min}$ after cycloheximide injection, pronounced extra expression was observed only in even-numbered parasegment interbands, whereas with 90 min of incubation, expression occurred in even- and odd-numbered parasegments (Fig. $7 \mathrm{~d}$. Consequently, we suggest that there are either different repressors in alternate interbands (Fig. 7b), or higher levels of the same repressors in the odd-parasegment interbands relative to the even-parasegment interbands. The latter possibility could arise because different pair-rule genes regulate the repressors in alternate engrailed interbands.

An overall conclusion from this study is that the onesegmental striped pattern of engrailed appears to be de-

Figure 7. A model for the spatial regulation of engrailed. (a) The normal pattern of engrailed expression is shown schematically as a repeating sequence of one expressing cell (dark box) separated by three nonexpressing cells (lightly shaded boxes). Also indicated are the positions of postulated repression systems which function in the nonexpressing cells: repression system 1 in the even-numbered parasegments and repression system 2 in the odd-numbered parasegments. ( $b$ ) Repression systems 1 and 2 are postulated to be the result of the combined action of repressors R1-R4 which delimit the anterior and posterior borders of each engrailed stripe. The same borders are defined from the opposite side by positive regulators A-D. From their patterns of expression (Kilchherr et al. 1986; Lawrence et al. 1987) and/or mutant phenotypes (Ingham and Martinez-Arias 1986), the regulators A-D may be the products of the even-skipped (eve), odd-paired (opa), fushi tarazu (ftz), and paired (prd) genes, respectively (Ingham et al. 1988). The patterns of A, B, and $C$ are simplified schematic representations of the patterns of eve, prd, and $f t z$ at approximately mid cycle 14, with only regions of strong expression indicated. In general, as embryos mature, the stripes become progressively narrower, and in the cases of $e v e$ and prd, extra stripes appear in the interbands later in cycle 14 (Kilchherr et al. 1986; MacDonald et al. 1986). Since opa has not been cloned, its assignment as gene D is based solely on mutant phenotypes, and its suggested pattern of expression is hypothetical (DiNardo and O'Farrell 1987; Ingham and Martinez-Arias 1986; Ingham et al. 1988). The hypothetical repressors R1-R4 could be the products of pair-rule or segment-polarity genes. Candidates for these genes are odd-skipped and naked (see text). (c) The positive regulation of engrailed by genes A-D could either be direct or indirect. If indirect, we postulate that A-D inactivate R1-R4, respectively, which in turn, directly repress engrailed, as illustrated. (d) Regions of engrailed expression (dark) and lack of expression (lightly shaded) are altered in embryos injected with cycloheximide and in mutant embryos. Extra interband expression of engrailed after treatment with cycloheximide is shown schematically in the first two lines: in the even-numbered interbands after 60 min of treatment, and in both even- and odd-numbered interbands after $90 \mathrm{~min}$ of treatment. Repression systems 1 and 2 have different sensitivities to cycloheximide. Known effects in embryos mutant for A, B, C, or D (lower two lines) can be accounted for by assuming either that A-D are direct positive regulators of engrailed, or by assuming that they are indirect regulators as shown in $c$. In the latter case, mutation in $A$ (eve), for example, results in the derepression of $\mathrm{R} 1$ which is therefore expressed at and represses odd-numbered engrailed stripes. Similar arguments hold for mutants in B-D. 
rived from two systems of negative regulation, each with two segmental periodicity, and 180 degrees out of phase with each other (repressions 1 and 2, Fig. 7a). This may reflect a more general developmental principle, namely that patterns with small units of spatial information can be defined by the out-of-phase superimposition of systems patterned in longer wavelengths.

\section{Experimental procedures}

\section{Embryo injection}

Injections were performed as described previously (Edgar and Schubiger 1986; Edgar et al. 1986a,b). Eggs were collected from 3- to 10-day-old adults ('Sevenlen' strain), and $10 \mathrm{~min}$ collections were obtained after $1 \mathrm{hr}$ precollection on fresh cornmeal food, followed by a 30-min and two 10-min precollections on agar plates supplemented with baker's yeast and glacial acetic acid. Embryos were staged by their morphology prior to injection (Edgar and Schubiger 1986; Edgar et al. 1986a). Cycloheximide and $\alpha$-amanitin were prepared in $5 \mathrm{mM} \mathrm{KCl}, 0.1 \mathrm{~mm}$ $\mathrm{NaPO}_{4}$ (pH 6.5), and were injected at $1 \mathrm{mg} / \mathrm{ml}$ (cycloheximide) or $0.4 \mathrm{mg} / \mathrm{ml}$ ( $\alpha$-amanitin). These were diluted about 50 -fold upon injection, assuming even diffusion throughout the egg (Foe and Alberts 1983).

\section{In situ hybridization}

At appropriate times after injection, embryos were embedded in a monolayer in OCT embedding compound (Miles) as described previously (Edgar et al. 1986b), and $8-\mu \mathrm{m}$ sections were prepared. In situ hybridization was with ${ }^{35} \mathrm{~S}$ - or ${ }^{3} \mathrm{H}$-labeled DNA or RNA probes prepared according to Kornberg et al. (1985) and Jorgensen and Garber (1987). The DNA probe was a 1.4-kb engrailed cDNA (Poole et al. 1985) in pUC mp8, and the RNA probe was transcribed from a 1.2-kb Rl Xho fragment of a 2.4$\mathrm{kb}$ engrailed cDNA (Poole et al. 1985) cloned in T7-2. Autoradiography was for 20-30 days for ${ }^{35} \mathrm{~S}$ probes and 30-60 days for ${ }^{3} \mathrm{H}$ probes.

\section{RNA blots}

RNA isolation and preparation of Northern blots was as described in Edgar et al. (1986b). Actually, the same blots from this previous study were reused here, probing with an antisense RNA probe made from a 553-bp Sal-Xho engrailed cDNA fragment in T7-1 (Poole et al. 1985). Each lane of the Northern blots in Figure 2 represents the total RNA extracted from $60 \mathrm{em}$ bryos. Several film exposures were analyzed by scanning densitometry, and values in the linear range of the film were used for the graphs in Figure 2.

\section{Acknowledgments}

We thank Bruce Alberts and Nick Baker for critical readings of the manuscript, Cynthia Kenyon, Steve DiNardo, Steve Poole, Tim Karr, and Victoria Foe for useful discussions, and Erik Jorgensen and Walter Soeller for technical advice. This work was supported by a fellowship from the Jane Coffin Childs Memorial Fund for Medical Research to M.P.W., a National Science Foundation Predoctoral Fellowship to B.A.E., and National Institutes of Health grants to T.K. (GM30637 and GM36506) and G.S. (GM33656).

\section{References}

Akam, M. 1987. The molecular basis for metameric pattern in the Drosophila embryo. Development 101: 1-22.

Baumgartner, S., D. Bopp, M. Burri, and M. Noll. 1987. Structure of two genes at the goosberry locus related to the paired gene and their spatial expression during Drosophila embryogenesis. Genes Dev. 1: 1247-1267.

Campos-Ortega, J.A. and V. Hartenstein. 1985. The embryonic development of Drosophila melanogaster. Springer-Verlag, Berlin.

Carroll, S.B. and M.P. Scott. 1986. Zygotically active genes that affect the spatial expression of the fushi tarazu segmentation gene during early Drosophila embryogenesis. Cell 45: $113-126$.

DiNardo, S., J.M. Kuner, J. Theis, and P.H. O'Farrell. 1985. Development of embryonic pattern in $D$. melanogaster as revealed by accumulation of the nuclear engrailed protein. Cell 43: 56-69.

DiNardo, S. and P.H. O'Farrell. 1987. Establishment and refinement of segmental pattern in the Drosophila embryo: spatial control of engrailed expression by pair-rule genes. Genes Dev. 1: 1212-1225.

Edgar, B.A. and G. Schubiger. 1986. Parameters controlling transcriptional activation during early Drosophila development. Cell 44: 871-877.

Edgar, B.A., C.P. Kiehle, and G. Schubiger. 1986a. Cell cycle control by the nucleocytoplasmic ratio in early Drosophila development. Cell 44: 365-372.

Edgar, B.A., M.P. Weir, G. Schubiger, and T. Kornberg. 1986b. Repression and turnover pattern fushi tarazu RNA in the early Drosophila embryo. Cell 47: 747-754.

Fjose, A., W.J. McGinnis, and W.J. Gehring. 1985. Isolation of a homeobox-containing gene from the engrailed region of Drosophila and the spatial distribution of transcripts. $\mathrm{Na}$ ture 313: 284-289.

Foe, V.E. and B.M. Alberts. 1983. Studies of nuclear and cytoplasmic behavior during the five mitotic cycles that precede gastrulation in Drosophila embryogenesis. I. Cell. Sci. 61: $31-70$.

Harding, K., C. Rushlow, H.J. Doyle, T. Hoey, and M. Levine. 1986. Cross-regulatory interactions among pair-rule genes in Drosophila. Science 233: 953-959.

Hiromi, Y. and W.J. Gehring. 1987. Regulation and function of the Drosophila segmentation gene fushi tarazu. Cell 50: $963-974$.

Hiromi, Y., A. Kuroiwa, and W.J. Gehring. 1985. Control elements of the Drosophila segmentation gene fushi tarazu. Cell 43: 603-613.

Howard, K. and P. Ingham. 1986. Regulatory interactions between the segmentation genes fushi tarazu, hairy, and engrailed in the Drosophila blastoderm. Cell 44: 949-957.

Ingham, P.W. and A. Martinez-Arias. 1986. The correct activation of Antennapedia and bithorax complex genes requires the fushi tarazu gene. Nature 324: 592-597.

Ingham, P.W., N.E. Baker, and A. Martinez-Arias. 1988. Regulation of segment polarity genes in the Drosophila blastoderm by fushi tarazu and even-skipped. Nature 331: 73-75.

Jackle, H., D. Tautz, H. Schub, E. Seifert, and R. Lehmann. 1986. Cross-regulatory interactions among the gap genes of Drosophila. Nature 324: 668-670.

Jorgensen, E.M. and R.L. Garber. 1987. Functions and misfunctions of the two promoters of the Drosophila. Antennapedia gene. Genes Dev. 1: 544-555.

Kilchherr, K., S. Baumgartner, D. Bopp, E. Frei, and M. Noll. 1986. Isolation of the paired gene of Drosophila and its spa- 
tial expression during early embryogenesis. Nature 321: 493-499.

Kornberg, T., I. Siden, P. O'Farrell, and M. Simon. 1985. The engrailed locus of Drosophila: in situ localization of transcripts reveals compartment-specific expression. Cell 40: $45-63$.

Lawrence, P.A., P. Johnson, P. Macdonald, and G. Struhl. 1987. Borders of parasegments in Drosophila embryos are delimited by the fushi tarazu and even-skipped genes. Nature 328: 440-442.

Lindquist, S., B. DiDomenico, G. Bugaisky, S. Kurtz, L. Petko, and S. Sonoda. 1982. Regulation of the heat-shock response in Drosophila and yeast. In Heat shock from bacteria to man (ed. M. Schlesinger, M. Ashburner, A. Tissieres) pp. 167-175. Cold Spring Harbor Laboratory, Cold Spring Harbor, New York.

Macdonald, P.M., P. Ingham, and G. Struhl. 1986. Isolation, structure, and expression of even-skipped: a second pairrule gene of Drosophila containing a homeo box. Cell 47: $721-734$.

Martinez-Arias, A. and P.A. Lawrence. 1985. Parasegments and compartments in the Drosophila embryo. Nature 313: 639642.

Martinez-Arias, A., N.E. Baker, and P.W. Ingham. 1988. Role of segment polarity genes in the definition and maintenance of cell states in the Drosophila embryo. Development 103: $157-170$.

Perrimon, N. and A.P. Mahowald. 1987. Multiple functions of segment polarity genes in Drosophila. Dev. Biol. 119: 587600.

Poole, S.J., L.M. Kauvar, B. Drees, and T. Kornberg. 1985. The engrailed locus of Drosophila: structural analysis of an embryonic transcript. Cell 40: 37-43.

Rabinowitz, M. 1941. Studies on the cytology and early embryology of the egg of Drosophila melanogaster. I. Morph. 69: $1-49$.

Weir, M.P. and T. Kornberg. 1985. Patterns of engrailed and fushi tarazu transcripts reveal novel intermediate stages in Drosophila segmentation. Nature 318: 433-439.

Zalokar, M. and I. Erk. 1976. Division and migration of nuclei during early embryogenesis of Drosophila melanogaster. $J$. Micro. Biol. Cell 25: 97-106. 


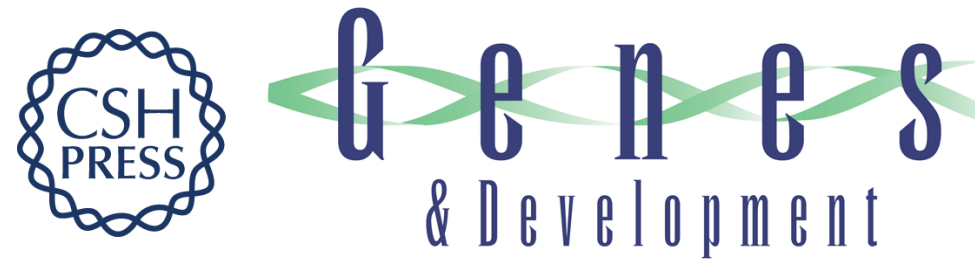

\section{Spatial regulation of engrailed expression in the Drosophila embryo.}

M P Weir, B A Edgar, T Kornberg, et al.

Genes Dev. 1988, 2:

Access the most recent version at doi:10.1101/gad.2.9.1194

References This article cites 29 articles, 7 of which can be accessed free at:

http://genesdev.cshlp.org/content/2/9/1194.full.html\#ref-list-1

License

Email Alerting Receive free email alerts when new articles cite this article - sign up in the box at the top Service right corner of the article or click here.

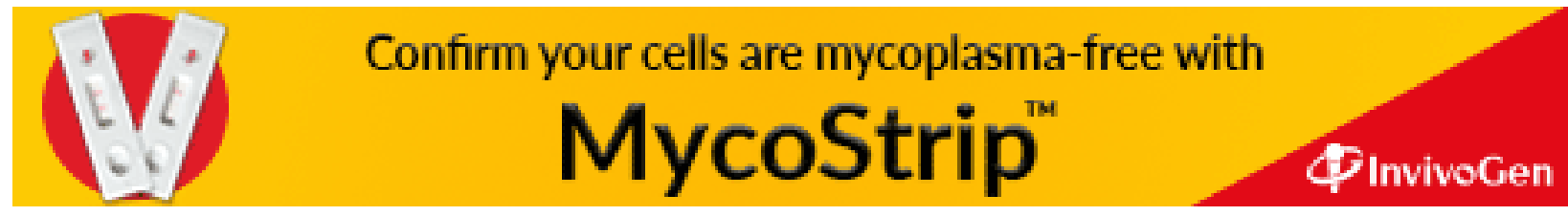

